\title{
Reading the methodological essay in twentieth-century economics : map of multiple perspectives
}

\author{
Mäki, Uskali \\ Cambridge University Press \\ 2009
}

Mäki , U 2009 , Reading the methodological essay in twentieth-century economics : map of multiple perspectives . in U Mäki (ed.), The methodology of positive economics : Reflections on the Milton Friedman legacy . Cambridge University Press, Cambridge, pp. 47-67.

http://hdl.handle.net/10138/232400

acceptedVersion

Downloaded from Helda, University of Helsinki institutional repository.

This is an electronic reprint of the original article.

This reprint may differ from the original in pagination and typographic detail.

Please cite the original version. 


\title{
Reading the methodological essay in twentieth century economics: Map of multiple perspectives
}

\author{
Uskali Mäki \\ To appear in \\ The Methodology of Positive Economics: \\ Milton Friedman's Essay After Half a Century, edited by Uskali Mäki. \\ Cambridge University Press.
}

\begin{abstract}
Even outrageously unrealistic assumptions are just fine insofar as the theory or model involving them performs well in predicting phenomena of interest. Most economists and many non-economists will attribute this principle to Milton Friedman. Many will consider the principle itself outrageous, while others praise Friedman for having formulated it so persuasively.
\end{abstract}

Friedman's "The methodology of positive economics" was published in 1953 as the opening chapter of his Essays in Positive Economics. There is no doubt that this short essay of 40 pages became the most cited, the most influential, and the most controversial piece of methodological writing in $20^{\text {th }}$ century economics. The power and diversity of its impact and reception is evident. The essay (henceforth 'F53') has helped shape many economists' conceptions of how to do good economics and how to defend certain ways of doing economics. It has also provoked many others to speak out their disagreement on the claims of the essay, to argue that the view of science suggested by F53 is deeply flawed, even dangerous for the cognitive aspirations and social responsibilities of economics. These disagreements have not diminished in the course of the years between now and the publication of F53. Whenever someone makes reference to "Friedman's methodological view" (perhaps using other expressions such as "Friedman's as-if methodology" or "Friedman's instrumentalism"), the context typically reveals that the expression is used either approvingly or disapprovingly, and often uncompromisingly so. 
The legacy of F53 has led a double life. In the last half a century, F53 has prompted numerous scholarly commentaries and criticisms in an attempt to understand and (mostly) to resist its message. But the influence of F53 evidently reaches far beyond such explicit commentaries. In fact its effective impact may have flown along its own separate ways, uninfluenced by the various criticisms that have been levelled against the essay. There has been a popular legacy of F53, based on a vague understanding of its key ideas, sustained and transmitted without any detailed analysis or reflection of the text of the essay, often without citation or reference. The popular legacy manifests itself in introductory chapters of economics textbooks in which students are being explained why the assumptions of economic models do not need to be realistic, and in oral communication at seminars and conference sessions as reference is being made to "as-if methodology" or the importance of predictive implications in testing models. Parallel to this popular legacy, and surely motivated by it, there has been a tradition of more or less systematic "F53 studies" aiming at detailed critical scrutiny of the claims and arguments of the essay. This has constituted what may be called the reflective legacy of F53. Numerous studies have been published in journals and books, critically analyzing and interpreting and explaining F53 from a variety of angles, focusing on its different aspects, and drawing conclusions that rival or complement one another. The present volume adds many important and novel insights and analyses to this body of reflective literature. It is hoped that they will have consequences for the contents of the popular legacy.

In both of these incarnations of its legacy, the popular and the reflective, F53 has been highly influential. It has shaped the perceptions of the economist-of-the-street, and it has provoked specialists in economic methodology to engage in serious scholarly studies in hermeneutic interpretation and analytical criticism. I should add the important observation that its influence is not restricted to the economics profession: F53 has shaped the image of economics also amongst other social scientists. One often comes across with statements about the nature of economic reasoning that make reference to F53, thereby suggesting that F53 gives a relatively accurate picture of how economics is being done by economists. In most such situations, the image is not intended as a flattering one. Indeed, many social scientists other than economists take it as evident that 
a discipline dependent on working with highly unrealistic assumptions is of dubious scientific value, thus a methodology seeking to justify such a practice must be at least equally suspect as a theory of science. To the extent that the broader public image of economics derives from F53, it is usually not one of praise and celebration.

Yet another very important motivating observation is that F53 seems to have been poorly understood. One might be surprised by this claim: given its strong impact, and given the large number of reflective commentaries that have appeared, one would expect F53 to be well understood by now. But this is surely not the case. On the one hand, strong impact, as in the popular legacy, is perfectly compatible with a poor understanding of what exactly makes that impact. Even more embarrassingly, poor understanding sometimes helps a piece of writing to make a popular impact. On the other hand, even though one might have higher expectations in regard to the explicitly reflective commentaries, they too may have failed to generate sufficiently solid understanding of F53 for understandable reasons. Some of these reasons derive from the fact that F53 is inherently very hard to understand. This difficulty is not only due to its richness, but also to its obscurities, ambiguities, and inconsistencies. One may even take these characteristics to support the radical conclusion that there is no single correct way of interpreting F53, rather there are multiple justifiable readings. Another possible reason for failure, or imperfect success, is the familiar mismatch between one's interpretive concepts (employed by readers) and one's target (the text). Any reflective commentary of a text approaches its target equipped with conceptual tools and philosophical frames, and these may not be appropriate for the task of getting the meaning of the text right. No doubt F53 has been approached from angles that are too limited or even plainly misguided to result in a solid understanding given the richness and complexity of F53 itself.

F53 was published half a century ago, but the interest in understanding and assessing the essay is not at all just historical. Its key claims remain as topical as ever: they are repeatedly being invoked by economists, generation after generation. Nowadays, they have special contemporary relevance in the context of the new debates around economic theory and method. In its own time, F53 was motivated by empirically based attacks 
against marginalist profit maximization. As Roger Backhouse explains in his chapter below, F53 can only be understood against the background of the so-called marginalist controversy in the 1940s. Together with Fritz Machlup's methodological polemics (Machlup 1946, 1955), F53 became a major defensive statement that sought to undermine the empirical criticisms that were levelled against marginalist maximization assumptions. Today, we are again witnessing massive attacks against the standard assumptions of rationality, and there are new attempts to replace them by more realistic assumptions. The difference is that in the late 1930s and early 1940s, the critical strategy was one based on field survey, simply asking business managers what they were doing, while nowadays the critical conclusions derive from experiment and brain scan, with psychologists and neuroscientists contributing to the collection of critical evidence. Even though F53 itself badly underestimated the role of experiment in economics, the topicality of its methodological arguments is evident.

F53 also set out to defend perfect competition against developments in the theory of monopolistic competition that F53 described as an entirely misguided pursuit of greater realisticness. As Oliver Williamson's chapter below shows, post-F53 developments in theories of the firm and market structure have not been obedient to these proscriptions, they have rather taken the theories towards opening the black box of the business firm and thereby towards more realistic images of motivation and procedure within firms. Monopolistic competition has also recently made a comeback packaged with increasing returns in explaining phenomena of growth and agglomeration. The challenge is to assess these developments in terms of F53 - and to assess F53 in terms of these developments.

The topicality of F53 is also fortified by the chronic difficulties in running reliable predictive tests in economics. The core principle endorsed by F53 appears to require that there be a set of well-defined and agreed-upon objective rules for measuring predictive success - given that predictive success is supposed to be all that matters in testing a theory. F53 itself does not formulate such rules, and as we know, economists constantly struggle with the consequences of not having such rules. Naturally, there are established practices of prediction and testing, but they are not - and cannot - be completely 
governed by explicit rules. Testing by prediction is far from anything straightforward and uncontestable. Paradoxically perhaps, F53 itself supports this claim, as I point out in my second chapter below. Indeed, there is a line of thought in F53 that seems to have been missed by most readers: predictive tests are not fully objective and reliable, they unavoidably involve subjective judgement and social convention. Whether or not this makes F53 a self-undermining piece of writing, it is obvious that it does imply a call for greater caution in appealing to predictive tests, and for greater attention to the details of the structure of actual predictive tests.

The above are among the features of F53 that taken together give sufficient grounds for organizing a collective reconsideration of the essay half a century after its publication. Contributions were commissioned from scholars with complementary interests and competences to offer insight into the conundrums of F53 from a variety of perspectives. The assignments were designed with the goal of having a number of analyses complementing one another, while avoiding excessive overlap between the contributions. Each contribution would have a separate focus, and together they would provide a comprehensive and rich - but still incomplete - picture of F53 in context. The contributors were asked to help a 21st century reader to have a reasoned opinion of F53, its contents and their descriptive and prescriptive adequacy. Meeting this challenge would be based on examining the text of the essay, its historical and intellectual context, and the developments of economics and its methodology after 1953.

Just like the various commentaries of F53 that have been published during the last half a century, the contributions to this volume approach F53 from different angles, addressing different questions and pursuing the answers by following different strategies. In order to assess the various contributions one has to understand what they seek to accomplish, what their goals and constraints and other presuppositions are. It may therefore be useful to outline a map of approaches to F53, providing beginnings of a typology of readings or interpretations. Such a map should help assess the readings in their own terms and to compare their merits and ambitions. 
In the remainder of this essay, I propose to organize the various ways of reading and examining F53, each of them giving rise to different types of project. I am thinking of a map that is on five dimensions. The first dimension is related to the functions of reading F53, from taking it as a target of critical examination to using it without examining it, for example as a source of information or inspiration. The second dimension consists of a range of internal characteristics of F53, from those of its elements that focus on the logical aspects of economic theorizing to those that highlight its ontological, semantic, and social aspects. The third dimension is constituted by a variety of external contexts of F53, from the context of its writing to the context of its reading and reception. The fourth dimension consists of perspectives that range from normatively assessing various features of F53 to analyzing and explaining those features. The fifth dimension is concerned with the sources of various labels attached to F53, from extra-economics to intra-economics, and more.

I will expand on this map and will illustrate by locating various contributions to "F53 studies" that have appeared in the course of the last half a century, including those published in the present volume.

\section{[1] Examining and using}

The first dimension has to do with the foci and functions of reading F53, ranging from examining it to using it. At one end, one may approach F53 as itself the primary target of study, examining and explaining it, analyzing and scrutinizing it, contextualizing and criticizing it, and so on. At the other end of the spectrum, the reader of F53 may take it as a source or means of information and inspiration, of persuasive argument and authoritative judgement, of reproach and ridicule. Here, without examining F53 itself, one may quote or cite it, and then proceed to focus on other things, such as the nature of economic models, contemporary debates in economic theory and method, issues around the public image of economics, or challenges of economics education. 
There is no dichotomy here, but rather a continuum of foci along this dimension. For example, many reflective readers of F53 nowadays examine the text of the essay in order to use the findings as evidence for an account of the methodological outlook of the author of F53 more broadly. In this case, one examines F53 but does not draw conclusions about F53 only, but may use the outcome of such investigations together with other sources of evidence for portraying Milton Friedman's methodology of doing economic research. This strategy appears in several studies, including the book on Friedman by Abraham Hirsch and Neil DeMarchi (1990), Daniel Hammond's and Thomas Mayer's various works, as well as the chapter below by Kevin Hoover.

This observation gives us an important distinction between examining F53 in order to understand F53, and examining F53 in order to understand Friedman's economics and its methodology. It is important to be explicit about the difference between the two goals of reading, given that they are not always kept distinct. Both are legitimate tasks, but they require different standards to be appropriately assessed. For example, in considering an interpretive attempt to understand F53 alone, one should not judge the attempt straightforwardly in terms of its success or failure to provide understanding of Friedman's economics. A good account of F53 may not be a good account of Friedman's methodology, in some cases not even part of it. Indeed, Friedman's methodology and the methodology of F53 are not one and the same thing, even though the two are likely to be connected. That they are not the same thing is exemplified, among other things, by incongruences between the dictates of F53 and Friedman's statements and practices elsewhere, such as unrealisticness of assumptions considered irrelevant here, but relevant there. It is notable that prior to the 1980s, virtually all commentary on F53 focused on F53 without any interest in Friedman's methodology. The situation has since then changed, perhaps due to the changes in Milton Friedman's status within economics: next to straight F53-studies, we now also have studies of Friedman's methodology.

Given that all the other dimensions on my map lean towards the examination side of the first dimension, I will not say more about this here, but will instead focus on the use side. The popular legacy of F53 is a matter of use without examination. As an example in this 
category, textbook authors sometimes make reference to F53 when explaining to the students why they should not worry about unrealistic assumptions.

In the present volume, all contributions are within the reflective legacy, but in some of them the use component is more pronounced than the examination component. Melvin Reder's chapter deals with the role of visions or general "frames" in economic theorizing, including offering an extensive discussion of contemporary debates over involuntary unemployment and sticky wages and other methodological issues concerned with what qualifies as evidence in economics. In these parts of Reder's chapter, F53 is not so much examined itself as it is used for launching the broader discussion. Also dealing with issues of evidence, the focus of Chris Starmer's chapter is on the articles on expected utility jointly authored by Friedman and Savage, published in the neighbourhood of F53, namely in 1948 and 1952. Pointing out parallels and incongruences between the methodological positions revealed in these articles and F53, Starmer raises critical questions about using normative appeal as indirect evidence in support of expected utility hypothesis. Starmer puts his observations also in the context of current debates over the assumptions of rationality.

The mixture of examination and use is similar in Oliver Williamson's chapter that discusses some key ideas of F53 in the context of the post-1953 developments away from the neoclassical theory of the firm defended by F53. These developments lead away from just one theory towards many theories, and from the unrealistic image of theories as production functions with profit maximization towards increasing realisticness in motivation, then in process. Jack Vromen's chapter can be seen as a combination of examination and use: tracing various pre-F53 and post-F53 versions of the evolutionary argument as designed and used by various economists, he manages to help us see the distinct characteristics of the argument as presented in F53 itself - while at the same time informing us about the variety of such arguments available in economics.

[2] Internal characteristics of F53 
The second dimension on my map consists of a range of internal characteristics of F53 noticed by the reader, namely what F53 itself is taken to say about economic theories and scientific reasoning, and how it says it. The accounts of F53 here focus on interpreting and assessing its stated or implied view of economics as a scientific discipline. The text of F53 serves as the main source of evidence for these accounts, while the goal is to identify and examine the claims and arguments of the essay. Given the richness of the internal characteristics F53, any reading is bound to be somewhat selective among them some more, some less - and there are many ways of making one's selections.

At one end, readers may focus narrowly on just how F53 deals with "assumptions", "predictive implications" and "data" as well as their logical relationships in economic theorizing. Most commentaries from the 1950s to the 1970s were largely constrained by this perspective, from Rotwein (1959) through Samuelson (1963) and Simon (1963) to Melitz (1965), Bear and Orr (1967), Brunner (1969), Wong (1973) and Boland (1979). F53 was read as stating that the truth of the assumptions of economic theories is irrelevant, and their falsehood is just fine, thus it makes no sense to try to test them against empirical data, while the assumptions entail predictive implications that are to be checked against the data, and this constitutes an appropriate test of the theory itself. Commentators then critically examined the logic of this argument about the logic of testing economic theory. Some of them recognized the ambiguity of 'assumption' in F53 and elsewhere, and checked the consequences with alternative specifications of the meaning of the term. Among the premises shared by many such narrowly logical accounts of F53 were the ideas that unrealisticness (of an assumption, or model) amounts to falsehood; that the falsehood of its assumptions amounts to the falsehood of a theory or model; and that assumptions are considered mainly from the point of view of their role in yielding predictions. Obviously, these premises enable creating a very limited image of F53.

The portrayal of F53 can then be enriched by adding a mixed variety of further characteristics to its description, including how F53 depicts the ontological, semantic, and social aspects of scientific reasoning. As for the ontological aspects, what does F53 
suggest regarding what is presupposed about the constitution of economic reality in economic theorizing? For example, does the profit maximization assumption presuppose something about the deliberations and purposeful activities of business managers or owners, or rather about the real pressures of the selection mechanisms of competitive markets? How is one to interpret Friedman's suggestion that the assumption of profit maximization summarizes the conditions of firm survival through natural selection in the competitive market? These questions have been discussed since Koopmans (1957) and Winter (1964). Jack Vromen's chapter below joins this tradition in his extended analysis of Friedman's selection argument in support of the maximization assumption. Chris Starmer devotes a section to this sort of argument in his chapter on expected utility. Kevin Hoover's discussion below on Friedman's poorly articulated attitudes towards real-world causation is another example of addressing ontological issues. Mere logical relations between sentences in a model are insufficient for capturing real causal connections.

Moreover, rather than just taking the truth-values of 'assumptions' and 'predictions' as given, and then examining their logical relationships, we may ask: What does F53 suggest regarding what it is for a theory and its assumptions to be true, or fail to be so? What functions do true and false assumptions serve in a model? How should we interpret the as-if formulation from the point of view of truth and falsehood, and what epistemic purpose is being served? What other ways are there for a theory or model to be realistic or unrealistic? These questions require attention to the precise claims about the world that theories and their components are used for making. For example, an assumption may appear false when formulated as a straightforward assertion about the world (the air pressure is nil, the market is perfect), but may have a chance of being true when rephrased as a claim about the negligibly small effect of some factor (the air pressure is negligibly small, the deviation from market perfection is negligible). This is a theme that was not perfectly lucid in F53, but was later introduced by Alan Musgrave (1981) and followed up in (Mäki 2000). There is another important idea that was not explicitly developed by F53, but on generous interpretation may be viewed as compatible with it. This is the idea that a model may appear false due to its narrowness and its containment 
of false assumptions, yet it may be used for making true claims about some significant facts about the world (Mäki 1992). This idea is further developed in my second chapter to this volume, as are the semantics and ontology of the as-if locution. Furthermore, next to truth and falsehood, there are other kinds of realisticness and unrealisticness that play important implicit roles in F53's reasoning, such as those related to observationality and partiality.

As to the social aspect of economic theorizing, what does F53 say or imply about the ways in which theorizing is shaped by various social factors within the academia and outside of it? These factors range from the enabling and constraining roles of academic communities and conventions to the pressures from economic policy and ideology. This has been a strikingly neglected theme in the legacy of F53, both popular and reflective. The chapter by Teira and Zamora in this volume looks at one aspect of F53 from the point of view of a contract between the "agents" (economists) and "principals" (consumers) of economic knowledge. My own work has stressed the central role of social shaping of economics in the reasoning of F53 and combines this with the rest of the spectrum, namely the logical, ontological, epistemological, and semantic perspectives (e.g., Mäki 1986, 1992, 2000).

\section{[3] External contexts of F53}

My map has another important dimension along which readings and commentaries of F53 are located. This third dimension consists of the range of external contexts of F53. 'External' here means external to F53, ranging from academic or intellectual contexts (such as the situation within economics and the philosophy of science) to political and broader cultural contexts in society at large - and both of these at the more particular level of Friedman's individual biography and at the more general level of academic and other social institutions. One may discuss F53 as a response to developments in economics and the philosophy of science, and one may examine its later impact on these developments. Most of the systematic commentary on F53, when paying attention to external contexts at all, has thus far focused on such more narrowly academic contexts. 
This is also the case in the present volume, even though observations about the economist expert (by Teira and Zamora) and free market ideology (by Reder) reach beyond the narrow academic horizons.

Let us make the discussion on external context more focused by drawing a distinction between the context of production and the context of consumption. At one end, the focus is put on the context of writing: the intellectual challenges and inspirations that provoked and shaped the production of F53 - such as the marginalist controversy triggering the textual production of F53, and the Marshallian tradition guiding it, as well as Friedman's own work as an economist and as a policy adviser. A prime example of these accounts is the book on Friedman's economics by Abraham Hirsch and Neil DeMarchi (1990). Among other things, they suggest ways in which Wesley Mitchell's methodological views may have influenced those of Friedman while at the NBER, and they point out what they claim to be close affinities between Friedman's methodology and John Dewey's pragmatist account of inquiry. Daniel Hammond's extensive work on Friedman's methodology and its origins is another major example in this category (e.g., Hammond 1996; on the idea of contexts, see Hammond 1992b).

These authors have been driven by the ambition of identifying Friedman's authentic convictions in economic methodology. They believe the internal characteristics of F53 alone do not suffice as evidence for those convictions, and that only when combined with lots of other evidence related to Friedman's work in economics and his broader intellectual background, can reliable conclusions be drawn about Friedman's real methodological beliefs. Hammond's contribution to the present volume, tracing the development of the early drafts of F53, examines the context or writing in almost as fine detail as it can get. Roger Backhouse's chapter examines the well-known role of the marginalist controversy in the context of writing F53. Complementing Hammond's story, Backhouse offers new information on the peculiar characteristics of F53 as a statement on theories of the firm and market structure by consulting the correspondence between Friedman and Don Patinkin in the late 1940s. Michel De Vroey's chapter deals with Friedman's convictions in relation to the Marshallian and Walrasian traditions. Chris 
Starmer casts new illumination on the methodological issues in Friedman's and Savage's joint work on expected utility and its role in inspiring some of the arguments in F53 such as the use of 'as-if' in formulating assumptions and the use of predictive tests in assessing theories. Teira and Zamora argue that the first section of F53 on the positivenormative distinction was motivated by Friedman's experience with policy advice. Painting with a broader brush, Melvin Reder's chapter situates F53 in the long tradition of the "frame" of the Invisible Hand of the free market.

At the other end, the focus is on the context of reading: of consumption rather than production, of ex post influence and reception rather than ex ante inspiration and creation. The context is that of the career of F53 once it was born. There are weak and strong versions of these 'consumptionist' accounts. The weak versions deal with the (actual, possible, desirable, inadvisable) reception and influence while at the same time keeping an eye on the author's beliefs and intentions. The strong versions bracket the author's attitudes entirely. Thomas Mayer's and Wade Hands's chapters below are largely in the weak consumptionist category. Their main interest lies in the reception and influence of F53, but they contrast this with what they view as Friedman's true beliefs and intentions. They raise questions about whether F53 has been read appropriately, whether its reception and influence is justified from the point of view of Friedman's authentic methodological convictions. For example, one may ask whether F53 licensed the "formalist revolution" as Wade Hands does and then answers in the negative (whereas a section in my second chapter suggests that F53 itself encouraged a "torso version" of its overall message, and that the torso version can easily be used for licensing formalism).

On the other hand, the strong consumptionist is only interested in the reader's reception rather than the author's intention. The goal is to read a methodological text from the point of view of its (actual or possible) reception by the relevant audiences, including its (actual or possible) interpretations and influences - while completely ignoring questions about the author's beliefs and goals. This is what I call "reception methodology" in analogy with reception aesthetics. My own second chapter purports to be a more or less 
pure exercise in reception methodology. The important difference between my chapter and those of Mayer and Hands lies in the fact that Mayer and Hands provide a role for the authentic beliefs and intentions of the author of F53, while I am bracketing them altogether and discussing the text of F53 only. A further difference is that Mayer and Hands write about the actual reception by others in historical terms, while I am offering my own novel reading of the essay. Theirs is a project of contrasting some other people's readings of F53 with their own reading of it, where their own reading is supposed to yield access to the views that the author of F53 really held. My project cannot be contrastive in that way since here I pay no attention to Friedman's true beliefs and intentions.

Powerful support seems to be available to such a strong receptionist approach: Milton Friedman himself has refrained from commenting the commentators of F53 in public, and he has done so deliberately. He made an early decision to let F53 live its own life, leaving it at the mercy of its readers as it were. This is confirmed in his "final word" at the end of the present volume. He has enjoyed watching the readings of, and debates over, F53 and has only privately provided feedback to its various interpretations. All this seems to offer strong support to the receptionist approach from the most authoritative source. There is a tension here, though. Reception methodology was supposed to ignore the author's beliefs and intentions, so it might seem inappropriate to appeal to this same author's stated intentions in defence of reception methodology. The obvious way of relieving the tension simply points out that one should not conflate the two levels of appeal to the author's attitudes: the levels of the justification of a reading and of the justification of a strategy of reading. The receptionist reading of F53 makes no appeal to the author's intentions, while it is at most the justification of the receptionist strategy that makes higher order appeal to the author's attitudes. Further relief is due to the fact that, in the end, the former is not dependent on the latter: we may adopt a receptionist strategy without Friedman's permission.

Another way of justifying a receptionist reading of F53 is based on the recognition that this is how most readers view F53 anyway. This is very much part of the popular legacy of F53, and this is part of much of the reflective legacy as well. Most readers are not in 
the least interested in Milton Friedman's peculiar intellectual trajectories or his authentic methodological convictions. They rather read F53 as a source of insights and arguments that they can put into use when themselves dealing with troubling methodological issues in economics. When connecting the methodological arguments of F53 to the practice of economics, readers do not usually connect them to Friedman's practice but rather to that of their own and of others, whenever it seems useful as issues of justification and critique of that practice arise.

The above remarks have dealt with the intra-academic context of F53. It should also be possible to put F53 in a broader extra-academic context. One could read it as being embedded in the cultural and political currents of its time, both reflecting and shaping them. Not only would this mean examining the image that F53 conveys of economics and of the economist expert as a politically powerful role - amongst the sciences, but also in society more broadly. The contribution by Teira and Zamora to this volume takes some steps towards this direction.

Further steps could be taken by locating F53 in a historically and politically unique external context. I have in mind a way of reading that has not been practised yet (not at least systematically), but that is not only a possible approach but also one that I anticipate will be attempted in the near future. This is based on recognizing a larger societal context in which the production and consumption of F53 have taken place. This larger context has to do with the overall transformations in the social sciences (and the philosophy of science) that took place in the 1950s and that have been linked with the broader sociopolitical conditions of the time, including the Cold War and the role of powerful funding agencies and research institutes (for examples, see Amadae 2003, Mirowski 2002, Reisch 2005). "Cold war history of science" is already a major stream of scholarly work, and it will not be surprising if there will be another small current of it within the flow of F53 studies. 


\section{[4] Evaluating and explaining}

The fourth dimension of my map has to do with whether F53 is being read from a normative or from an explanatory perspective. At one end, one sets out to evaluate the soundness of the claims and arguments put forth in the essay. Most evaluations in the reflective legacy have been critical of the contents of F53. These include commentaries such as those by Koopmans (1957), Rotwein (1959), Samuelson (1963), Melitz (1965), Caldwell (1980), Blaug (1980), and Hausman (1992).

Many of these criticize F53 for failing to see that good science not only pursues predictive success but also asks and answers explanatory why-questions about the phenomena investigated - and in answering such questions, the assumptions cannot be too much off the mark. Others point out that even an economist interested in reliable predictions should prefer realistic assumptions. Some question the objectivity of the reliance on the predictive performance of economic theories without spelling out very precise standards in terms of which to measure such performance. Many critics also complain about the apologetic and complacent attitude endorsed by F53: its arguments seek to justify a dogmatic commitment to perfect competition and profit maximization against empirical challenges. Another class of criticisms claim to identify mistaken statements in F53 (such as claiming that the Walrasian rendering of monopolistic competition theory is motivated by photographic accuracy). Yet another set of complaints (my favourite) points out the strategic function of ambiguities and inconsistencies in the reasoning of F53, as well as incompatibilities between F53 and Friedman's practice as an economist (such as defending unrealistic assumptions in some situations and criticizing them in other contexts; suggesting to rely on the objectivity of predictive tests while denying their objectivity; holding dogmatic attitudes while advocating strong fallibilism).

So the mainline of evaluative readings have been critical, and indeed only a minority of reflective readings, such as Karl Brunner's (1969), have been supportive, usually with qualifications. Many evaluations are mixtures of approval and disapproval. In his chapter below, Williamson criticizes F53 for an anti-pluralist endorsement of a single all-purpose 
theory of the firm while admitting that the central idea of F53, namely testing theories by predictions, is basically right. My own reading of F53 is a mixture of praise and blame. The popular legacy is a different story again: the proportion of favourable evaluations of F53 has been larger than within the reflective legacy. Evaluations in this class typically do not come with qualifications; they express simple attitudes in terms of yes-yes, or nono. ${ }^{1}$

In all evaluative judgements of F53, one invokes, explicitly or implicitly, a set of standards. Such standards are concerned with the desirability and possibility of things such as truth, reliability, explanation, causal knowledge, predictive success, epistemic progress, consistency, consensus, and value-freedom. Further investigations are needed to turn such standards explicit whenever they are implicit, to specify the various meanings of such key terms whenever there is vagueness and ambiguity, and to identify and critically examine further presuppositions whenever there is conflict between, or disagreement over, those standards. For example, one needs to subscribe to the standard of consistency between scientific disciplines regarding their theories and empirical results if one sets out to blame an economist or an economic theory for ignoring evidence produced by experimental psychology.

While evaluation is one project, another task is to explain F53. We can exploit the ambiguity of 'explain' here and divide this into two types of exercise. The first kind of exercise aims at explaining what the various phrases and arguments in F53 mean, how they are best understood (this can also be called an analytical activity). Naturally, this is a task that must be taken before evaluation. One must understand what one wants to evaluate before actually evaluating it. But this principle is not always respected. The obvious suspicion is that within the popular legacy, normative judgement is easily passed

\footnotetext{
${ }^{1}$ In his "final word" at the end of this volume, Milton Friedman exercises some playful selfcriticism, saying that had F53 been more lucid, commentators would have silenced by now. This contrasts with his spoken statement, conveyed via a telephone connection at the panel discussion on the occasion of the $50^{\text {th }}$ anniversary of F53 at the ASSA Meetings (in Washington DC, January 2003). He said he recently reread F53 and found its claims basically right. Had he been a perfect "receptionist" about F53 himself, he would have said neither of these things.
} 
without any solid understanding of the arguments and claims of F53. This is understandable as it is almost definitive of the popular legacy that no deep and detailed reflective understanding is sought to support the assessment. But it is clear that the reflective legacy has also failed to produce consistently sound understandings of the message of F53. This is evident, among other things, in the multiplicity of incompatible philosophical labels attached to F53. It is also notable that while Boland (1979) claimed that all previous critics have failed to understand F53, it can be argued that Boland himself is in that same boat.

The second use of 'explain' is in terms of answering various why- and how-questions about F53. Why and how was the essay written the way it actually came about? Why and how was it received, or could have been received? For example, combining this with the focus on the context of writing, one may argue: this is how Friedman came to hold these views, and/or this is what he intended to mean by what he wrote. Dan Hammond's work exemplifies this approach. The work of many others, including my own, is a combination of the normative and explanatory perspectives.

Using these categories, one may envision a distinction between reading F53 philosophically and reading it historically. In reading F53 philosophically one adopts the first kind of explanatory perspective that aims at interpreting and analyzing intended or possible meanings and arguments in F53, and based on some interpretation, the reader may adopt an evaluative perspective, assessing the soundness of its claims. In reading F53 historically, one adopts the second kind of explanatory perspective, describing and explaining the temporal trajectory of relevant ideas - those in F53 as well as those that have shaped it and those that it has shaped - at personal and social levels. These two ways of reading complement one another usefully, and can also be combined with one another. 
[5] Extra-economic and intra-economic labels

It is only natural that the message of a complex text such as F53 will be simplified in terms of supposedly informative labels that help classify and characterize its message as distinctive. Since the 1970s, labelling the message of F53 has been a major task taken by its reflective readers. The labels have mostly come from extra-economic sources, namely philosophy: F53 has been classified as exemplifying this or that particular position in the philosophy of science. A few others have characterised Friedman's position as 'Marshallian', using an intra-economic label. And there are other possibilities. This is the final dimension on my map.

A number of philosophical labels have been ascribed to Friedman and F53 (mostly by readers who are professional economists). The view has been labelled as positivist, falsificationist, conventionalist, pragmatist, and instrumentalist - and as realist, social constructivist, and radical fallibilist in my own unconventional reading of F53. Of these, 'instrumentalism' has become the most popular label attached to F53. Very roughly, according to an instrumentalist conception of scientific theory, a theory is an instrument or tool for some purpose, such as problem solving or organising the empirical data. Such instrumental purposes must be other than truthfully representing the way in which the phenomena of interest come about - the latter is how realism would see the tasks of theorizing. Given that Friedman argues that it is all right for the assumptions of a theory to be false as long as the theory predicts well, instrumentalism has appeared to be his philosophy of economic theory.

Insofar as I have been able to determine, 'instrumentalism' was first explicitly used by Bear and Orr (1967) in characterizing Friedman's views. Later on, it was used by commentators such as Wong (1971), Boland (1979), Blaug (1980), and Caldwell (1980, 1990). However, the priority on this matter should perhaps go to philosopher of science Ernest Nagel. His authoritative treatise The Structure of Science appeared in 1961. The book contained a substantial discussion on conceptions of scientific theory, classifying them into what he called 'descriptivist', 'instrumentalist', and 'realist' views (Nagel 
1961). In December 1962, the American Economic Association Meetings included a panel session devoted to F53, featuring Paul Samuelson, Herbert Simon, Andreas Papandreou, Sherman Krupp, Fritz Machlup, and Nagel. In that session, Nagel (1963) suggested a possible interpretation of F53 as largely instrumentalist, but he did not use the term 'instrumentalism' (even though he used the expression "theory as a useful instrument"). I presume he could have easily done so, but my guess is that because he was addressing an audience mainly consisting of economists, he did not want to burden his account with unnecessary philosophical labels.

But is the instrumentalist reading right? This still remains a legitimate question. Contributing to the establishment of the instrumentalist interpretation of F53, Larry Boland's 1979 paper in the Journal of Economic Literature put forth the claim that F53 is a coherent defence of an instrumentalist conception of economics. This claim has two components in it, one about coherence and the other about instrumentalism. Since the publication of Boland's paper, I have disputed both of these claims. I have argued that what F53 offers is far from a coherent and unambiguous argument for any well defined position, and also that the most plausible interpretation of F53 (and perhaps Friedman's methodology in general) is based on the opposite of instrumentalism, namely realism (Mäki 1986, 1992, 2000). My contribution to this volume provides a detailed reading of F53 in realist terms. The key to this revisionist reading is to reconsider the functions of falsehood in economic models. Also in this volume, Kevin Hoover gives further support to the realist reading of Friedman's methodology by offering evidence from Friedman's work in monetary economics. The instrumentalist interpretation of F53 used to be the dominant one, but may have to give way to a diametrically opposing realist reading.

The broad variety of attributions is likely to be partly due to incompetent or relaxed use of the philosophical labels, but part of the reason may be rooted just in the ambiguities and inconsistencies of F53 itself. For example, to claim that F53 is a positivist statement simply because of its adherence to the positive/normative distinction might be taken as an example of philosophical incompetence if no other evidence is offered (or else it might be just a matter of using the label in a very narrow sense). There are a few other 'positivist' 
elements in F53 (see Mäki 1986), but they are not dominant (at the same time we should grant that the label 'positivist' has itself become disturbingly vague and uninformative). Similarly, there is a falsificationist element in F53 (the notion of failure to be contradicted by evidence), but it appears just in passing. Social constructivist features such as the emphasis on the role of disciplinary culture in shaping scholarly judgement are far more central to the argument of F53, even though they have been mostly ignored by the readers.

It has been suggested that Friedman was not a professional philosopher and therefore F53 should not be interpreted and judged in philosophical terms. This suggestion has been made by commentators such as Daniel Hammond, Thomas Mayer, and Kevin Hoover, also in this volume. When viewed through philosophical lenses, F53 may emerge as uninformed and obscure. The suggestion is that Friedman's methodology should instead be inferred from his work as an economist and as being embedded in the tradition of economics. This approach then is argued to suggest that the proper label for characterizing Friedman's methodology is 'Marshallian' - a label that is intra-economic in that it derives from within the tradition of economics itself rather than being imposed from outside economics, using philosophical labels such as 'positivist' and 'instrumentalist'.

I have three responses to this suggestion. First, I believe it will be fruitful to consider the intra-economic and extra-economic perspectives as complements rather than substitutes. They usefully complement and cross-check one another rather than exclude each other as incompatible rivals. Second, while it is obvious that F53 is not to be celebrated for its elaborate philosophical clarity and systematicity, I do think F53 is a delightfully useful piece of writing from a philosophical point of view. It is a rich pool of philosophically intriguing insights that pose difficult challenges to the philosophical analysis of economic theorising and reasoning. Moreover, published in 1953, many of its ideas anticipated later "post-positivist" ideas and arguments in the philosophy of science (such as the centrality of disciplinary community and culture, theory-ladenness of observations, and the underdetermination of theories by data). Pointing this out has been a theme in my 
contributions to the F53 studies and it is also one theme in my second chapter to this volume. Third, while it is obvious that due to the ambiguities of F53 the message of the essay is hard to characterize using a single philosophical label, it may be equally problematic to identify Friedman's methodology as 'Marshallian' due to the simple fact that 'Marshallian' is far from an unambiguous label itself, with fixed and well-defined contents.

Friedman himself drew a distinction between "Marshallian" and "Walrasian" ways of doing economics and elsewhere - not in F53 - identified his own approach with the Marshallian mode. He actively portrayed his position in negative terms by levelling criticisms against what he depicts as the unacceptable "Walrasian" approach. As pointed out by Michel DeVroey in this volume, Friedman's understanding of "Walrasian" was not fully coherent and historically accurate. It will not be surprising if the opposing "Marshallian" label were to suffer from similar unclarities.

Hence, whether using philosophical labels (such as 'instrumentalism') or intra-economics labels (such as 'Marshallian'), one cannot escape the hard task of offering further detailed specifications and elaborations. One has to look into the details of F53 and Friedman's economics (and whatever other things are relevant) to make progress in understanding Friedman's methodology (or in just understanding F53, were this to be the goal). Interaction and collaboration between philosophical concepts and those derived from within economics (while granting that there is no strict boundary line between the two) will be advisable in future investigations.

An extreme conclusion would be to label Friedman's methodological position simply as 'Friedmanian'. This 'intra-Friedmanite' strategy would have the advantage of evading the problems of extra-economic and intra-economic labels of the above kind. Yet the task would not be easy. How would one go about in selecting the relevant features of the various methodological statements and practices that can be ascribed to Friedman? Would one include a comprehensive and complex set of details and peculiarities, throughout his intellectual career and across various rhetorical contexts, not forgetting 
about the numerous inconsistencies within and between those statements and practices? This would single out the position as unique and unlike any other position actually or potentially held by others. Or should one rather pursue a generous interpretation that would ignore the ambiguities and inconsistencies and try to capture the simple and abstract 'essence' of Friedman's methodological position, perhaps by way of comparing and contrasting Friedman's statements with those of relevant others? This, too, might end up with describing a unique position. (Note that one may also choose to include some of the inconsistencies in one's depiction of the simple essence of Friedman's position - or the position of F53.) On top of such strategic choices, this line also involves the challenge of collecting and processing masses of textual and other evidence that contributes to the contents of the label 'Friedmanian' methodology. ${ }^{2}$ Anyhow, when pursued on a broad front in search for Friedman's methodology, this line has mainly historical relevance. In contrast, a reception methodologist reading F53 only from the point of view of its later receptions and functions is relatively uninterested in the contents of 'Friedmanian methodology', provided they have no major consequences for the reception of F53.

Finally, it is also possible to use intra-F53 labels when characterising the message of F53. One such possibility would be to say F53 exemplifies a "predictivist" position. Indeed, even though the very term 'predictivism' does not appear in the text of F53, it seems an appropriate derivative of the repeated emphasis in F53 on the role prediction as the goal and standard of economic theorizing. Another intra-F53 label is to say that it endorses an "as-if methodology". This might appear even more accurate given that F53 formulates many hypotheses in terms of the 'as-if' locution.

Again, the intra-F53 strategy of labelling is no less problematic than the other three strategies. This is because neither of the labels, 'predictivism' or 'as-if methodology', is able to fix a well-defined and distinctive methodological position. Indeed, many different and rival methodological views put stress on prediction, and likewise the as-if locution

\footnotetext{
${ }^{2}$ That the task would not be easy is revealed by Hammond's (1992a) interview with Friedman on the latter's methodology: the interview is revealing in that in manages to reveal so little, suggesting that perhaps there is little more there to be revealed concerning the 'essence' of Friedman's consciously held methodology.
} 
can be employed to express a number of different ideas with a number of different philosophical commitments. Just as with the other three labelling strategies, this gives rise to the further need to provide more detailed analyses, this time of the different meanings and uses of both prediction and the as-if. Thus to say that the central message of F53 is the importance of testing theories by their predictive implications, as Williamson does in his chapter, is not yet detailed enough to distinguish Friedman or F53 from many other similar but rival views.

My response to all four strategies of labelling - extra-economic, intra-economic, intraFriedmanite, intra-F53 - has been the same. Labels are useful and necessary, but if unsuccessful, they can be uninformative and even misleading. To make them accurate and informative, more details and qualifications are needed about the targets they are used for naming, and about the purposes these labels are intended to serve. Providing such details and qualifications is the task of careful empirical and conceptual inquiry into the available textual and other evidence. The present volume sets out to contribute to just such inquiry.

\section{References}

Amadae, S.M (2003) Rationalizing Capitalist Democracy. The Cold War Origins of Rational Choice Liberalism. Chicago: University of Chicago Press.

Bear, D.V.T. and Daniel Orr (1967) Logic and expediency in economic theorizing, Journal of Political Economy, 75, 188-196.

Blaug, Mark (1980). The Methodology of Economics. Cambridge: Cambridge University Press.

Boland, Larry (1979). A Critique of Friedman's critics, Journal of Economic Literature, 17, 503-22.

Brunner, Karl (1969). 'Assumptions' and the cognitive quality of theories, Synthese, 20, 501-25. 
Caldwell, Bruce (1980). A critique of Friedman's methodological instrumentalism, Southern Economic Journal, 47, 366-74.

(1992). Friedman's predictivist methodological instrumentalism - A modification, Research in the History of Economic Thought and Methodology, 10, 119-28.

Friedman, Milton (1953). The methodology of positive economics, pp. 3-43 of his Essays in Positive Economics. Chicago: Chicago University Press.

Hammond, J. Daniel (1992a). An interview with Milton Friedman on methodology, Research in the History of Economic Thought and Methodology, 10, 91-118.

(1992b). The problem of context for Friedman's methodology, Research in the History of Economic Thought and Methodology, 10, 129-47

(1996). Theory and Measurement: Causality Issues in Milton Friedman's Monetary Economics. Cambridge: Cambridge University Press

Hausman, Daniel (1992) "Why look under the hood?" in his Essays in Philosophy and Economic Methodology. Cambridge: Cambridge University Press.

Hirsch, Abraham and de Marchi, Neil (1990). Milton Friedman: Economics in Theory and Practice. Hertfordshire: Harvester Wheatsheaf.

Koopmans, Tjalling C. (1957) Three Essays on the State of Economic Science. New York: McGraw-Hill.

Machlup, Fritz (1946) Marginal analysis and empirical research. American Economic Review, 36, 519-554.

(1955) The problem of verification in economics. Southern Economic Journal, $22,1-21$.

Mäki, Uskali (1986). Rhetoric at the expense of coherence: A reinterpretation of Milton Friedman's methodology, Research in the History of Economic Thought and Methodology, 4, 127-143.

(1992). Friedman and realism, Research in the History of Economic Thought and Methodology, 10, 171-195.

(2000) Kinds of assumptions and their truth: Shaking an untwisted F-twist, Kyklos, 53, 303-322.

Melitz, Jack (1965) Friedman and Machlup on the significance of testing economic assumptions, Journal of Political Economy, 73, 37-60. 
Mirowski, Philip (2002) Machine Dreams. Economics Becomes a Cyborg Science. Cambridge: Cambridge University Press.

Musgrave, Alan (1981). 'Unreal assumptions' in economic theory, Kyklos, 34, 377-387.

Nagel, Ernest (1961) The Structure of Science. London: Routledge and Kegan Paul.

Nagel, Ernest /1963) Assumptions in economic theory. American Economic Review, 53, 211-219.

Reisch, George A. (2005) How the Cold War Transformed Philosophy of Science. Cambridge: Cambridge University Press.

Rotwein, Eugene (1959) On 'The Methodology of Positive Economics'. Quarterly Journal of Economics, 73, 554-575.

Samuelson, Paul (1963). Problems of methodology - Discussion, American Economic Review, Papers and Proceedings, 53, 231-236.

Simon, Herbert (1963). Problems of methodology - Discussion, American Economic Review, Papers and Proceedings, 53, 231-236.

Winter, Sidney G. (1964), Economic 'natural selection' and the theory of the firm, Yale Economic Essays, 4, 225-72.

Wong, S. (1973). The 'F-twist' and the methodology of Paul Samuelson. American Economic Review, 63, 312-25. 